\title{
Identifikasi model ruang bermain anak TK di Kota Samarinda sesuai kurikulum 2013 tentang lingkungan alam
}

\author{
Sherly Vernanda Rosalina ${ }^{1}$, Anak Agung Gede Sugianthara ${ }^{1 *}$, Ni Wayan Febriana Utami²
}

1. Prodi Arsitektur Pertamanan, Fakultas Pertanian, Universitas Udayana, Indonesia 80236

*E-mail: sugianthara@unud.ac.id

\begin{abstract}
Identify on model of kindergarten playground in Samarinda City based on curriculum 2013 about environmental education. This research is motivated by the absence of data from the identification of children's kindergarten play area in three kindergarten located in Samarinda City, namely TK Kartika V-11, TK Tunas Mulia and TK Islam Bunga Bangsa. This study aims to provide data on park quality and activities of hardscape and softscape implementation at Kindergarten locations. This study uses supporting data from the 2013 early childhood curriculum on the natural environment. The research method used survey method with data collection technique through observation, literature study, interview and questionnaire to respondent. The results of the analysis showed the identification data of children playground model so that it can then be compared with the conformity with the standard quality of McDowell and McDowell Criteria (1998) and Stigsdotter and Grahn (2002) with the modification format with Key Perfomance Index (KPI) according to Arifin, et al (2008). The assessment stage in the park was done on park elements, implementation and user activities by confirming the respondent and verifying park users against the location. The stages of this research were to produce recommendation of identification result from three kindergarten locations as descriptive recommendation and to produce better perception of application on children play room model according to the 2013 early childhood curriculum about knowledge in introducing natural environment.
\end{abstract}

Keywords: identification, key perfomance index (KPI), kindergarten, model of children playground, Samarinda City

\section{Pendahuluan}

Taman Kanak-kanak (TK) didirikan untuk membantu pertumbuhan dan perkembangan jasmani dan rohani anak didik di luar lingkungan keluarga sebelum memasuki pendidikan sekolah dasar, sehingga pentingnya suatu kegiatan yang sesuai dengan tuntutan, kebutuhan, dan minat anak agar potensi yang ada pada anak dapat berkembang secara optimal. Menurut Moore (1990) aktivitas anak pada ruang bermain dapat mempengaruhi perkembangan anak dalam terbentuknya kepribadian anak sejak dini sehingga penerapan ruang bermain yang berfungsi dengan baik sangat diperlukan untuk anak. Taman Kanak-kanak harus memberikan ruang eksplorasi alam secara optimal bagi anak-anak agar mempunyai ruang bermain sambil belajar yang berfungsi dengan baik sehingga dapat meningkatkan potensi minat dan bakat anak karena ditunjang oleh fungsi dan estetika taman yang baik.

Berdasarkan Permendikbud No.146 Tahun 2014 tentang kurikulum 2013 PAUD lampiran 1 mengenai Kompetensi Dasar Kelompok 3 terdapat sub bab 3.8 tentang mengenal lingkungan alam pada hewan, tanaman, cuaca, tanah, air, batu-batuan dan lainnya. Anak-anak diharapkan untuk peduli terhadap lingkungan alam dan bagaimana dapat mencintai, merawat dan mengerti tentang tanaman. Fenomena saat ini, kurangnya ruang bermain anak yang memiliki ikatan dengan lingkungan mempengaruhi psikologis anak dalam menghargai lingkungan. Usia dini merupakan periode awal yang paling penting dan mendasar di sepanjang rentang pertumbuhan dan perkembangan kehidupan manusia sehingga dari usia dini penting untuk meningkatkan perkembangan fisik dan motorik anak. Menurut data dari Dinas Pendidikan Kota Samarinda, terdapat 482 PAUD di Samarinda yang tersebar di 67 kelurahan di kota Samarinda. Menurut data SK Hasil Akreditasi BAP PAUD di Kalimantan Timur terdapat 150 PAUD/TK yang memiliki akreditas yang baik. Terdapat tiga TK yang dipilih karena memenuhi kriteria akreditasi A dan memiliki fasilitas taman yaitu adalah TK Kartika V-12, TK Tunas Mulia, TK Islam Bunga Bangsa. Fungsi taman tidak hanya menjadi estetika tetapi dapat berfungsi menjadi sarana pendidikan bagi anak sehingga mengidentifikasi taman TK yang berada di kota Samarinda sesuai dengan penerapan Kurikulum PAUD 2013 pada bagian pengetahuan 
Lingkungan alam terkhususnya pada penerapan fungsi dan estetika untuk memberikan referensi model penerapan taman sesuai dengan kurikulum tentang lingkungan alam yang dapat dijadikan sebagai referensi oleh instansi pendidikan TK dan pemerintah.

\section{Metode}

\subsection{Lokasi dan Waktu}

Penelitian ini dilakukan di kota Samarinda, Kalimantan Timur pada bulan Februari 2018 sampai dengan bulan April 2018 pada tiga lokasi TK yaitu TK Kartika V-11, TK Islam Bunga Bangsa dan TK Tunas Mulia.

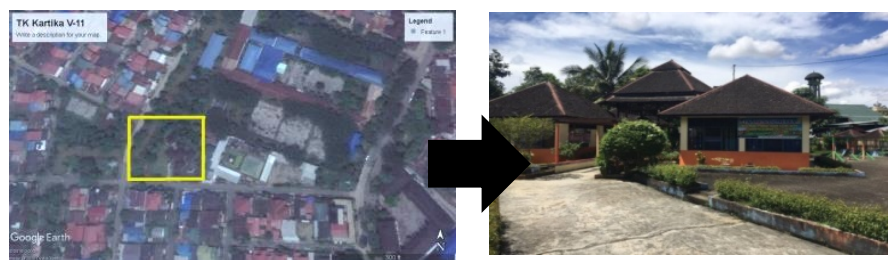

b. Peta Lokasi TK Tunas Mulia

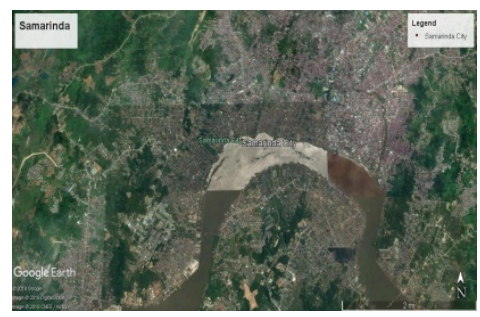

a. Peta Samarinda

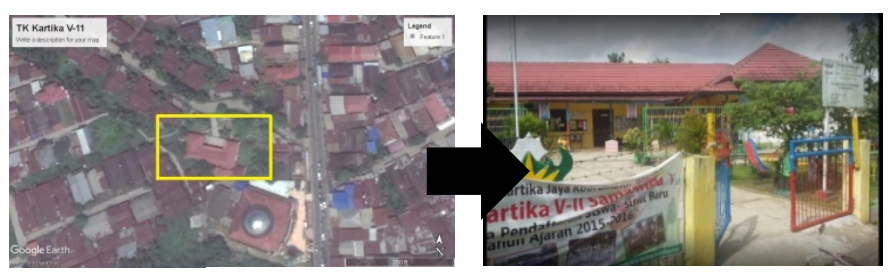

c. Peta Lokasi TK Kartika V-11

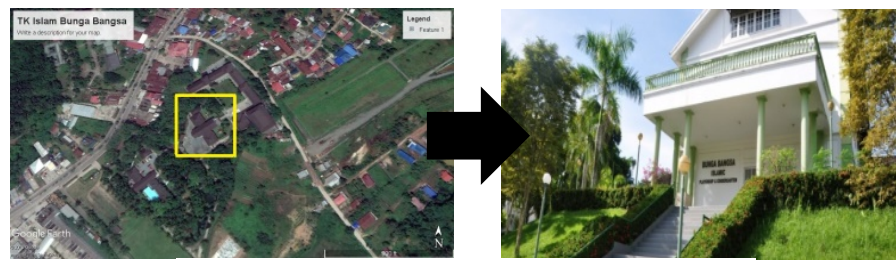

d. Peta Lokasi TK Islam Bunga Bangsa

Gambar 1. Lokasi Penelitian

\subsection{Alat dan Bahan}

Alat yang digunakan dalam penelitian ini adalah kuesioner untuk mendukung survei, tabel kriteria standar desain fungsional untuk penilaian pada penerapan Kurikulum PAUD 2013.

\subsection{Metode Penelitian}

Penelitian menggunakan metode survei dengan teknik observasi, studi pustaka, wawancara dan pemberian kuesioner kepada responden. Obersvasi dilakukan untuk mendapatkan data di lapangan pada hardscape dan softscape, wawancara dan pemberian kuesioner mengetahui tingkat pengetahuan dan kepedulian pengajar kepada taman yang baik untuk anak. Teknik sampling yang digunakan adalah purposive sampling dengan memilih tiga TK yang terakreditasi A.

\subsubsection{Persiapan}

Tahapan ini merupakan tahapan dilakukan identifikasi masalah yang terdapat pada lokasi penelitian dan melakukan studi literatur sebagai bahan panduan dalam memperoleh data dan proses analisis.

\subsubsection{Inventarisasi}

Tahapan ini merupakan pengumpulan data pada aspek fisik, desain dan sosial untuk mengetahui kualitas taman, ruang-ruang taman, elemen pada taman serta fasilitas dan utilitas pada ketiga lokasi TK. Data sosial pada taman mendapatkan hasil evaluasi pada anak dalam menggunakan fasilitas taman untuk mengetahui tingkat kecerdasan komprehensif pada permainan. 


\subsubsection{Kriteria Desain Fungsional}

Metode analisis data dengan analisis deskriptif untuk mengetahui fungsi dan aktivitas pengguna dan analisis kualitatif pada pengajar untuk mengetahui persepsi pengajar mengenai informasi taman dalam keindahan dan kenyamanan dalam taman anak untuk penerapan Kurikulum PAUD 2013 materi tentang Lingkungan Alam. Melakukan analisis dengan format yang dimodifikasi dengan penilaian Key Perfomance Index (KPI) menurut Arifin, et al (2008) untuk mengetahui hasil identifikasi fungsi taman mengacu pada kriteria desain menurut McDowell dan McDowell (1998) dan Stigsdotter dan Grahn (2002) dengan rumus:

$\mathrm{KPI}=\quad \frac{\text { Nilai Aktual }}{\text { Nilai Standar }}$

Cara penilaian adalah dengan membubuhkan tanda $(\sqrt{ })$ pada kolom evaluasi nilai aktual yang sesuai dengan selang nilai 1 sampai 3, dengan keterangan $1=$ tidak baik, 2=cukup baik, 3=sangat baik. KPI ini diperoleh dari hasil perhitungan jumlah nilai aktual dibagi dengan jumlah nilai standar berdasarkan indikator penilaian. Penilaian kriteria desain disajikan pada Tabel 1.

Tabel 1. Penilaian Kriteria Desain Fungsional

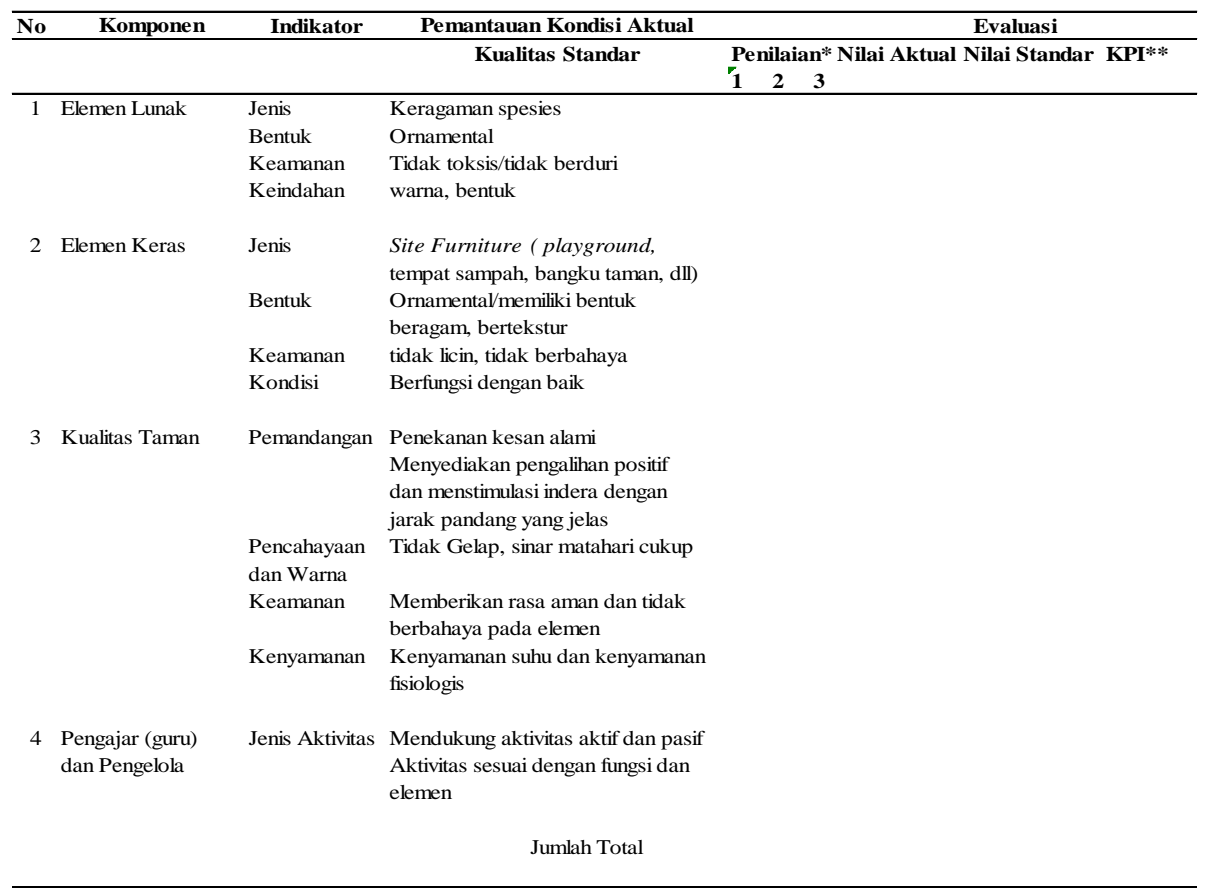

Keterangan :

*Nilai 1: tidak sesuai dengan kriteria standar, Nilai 2: kurang sesuai dengan kriteria standar, dan Nilai 3: sesuai dengan kriteria standar

**KPI: Key Performance Index (Format tabel berdasarkan modifikasi dari Arifin, Munandar, Arifin, Pramukanto, dan Damayanti (2008)

\subsection{Batasan Penelitian}

Penelitian ini dibatasi sampai menghasilkan rekomendasi dari hasil identifikasi, wawancara dan penyebaran kuesioner dari tiga lokasi taman pada TK sebagai rekomendasi secara deskriptif dan menghasilkan persepsi penerapan yang lebih baik pada model ruang bermain anak yang sesuai pengetahuan dalam pengenalan lingkungan alam.

\section{Hasil dan Pembahasan}

\subsection{Gambaran Umum Lokasi}

Penelitian pada lokasi TK mengambil tiga lokasi TK yang digunakan sebagai tempat penelitian yaitu TK Kartika V-11, TK Tunas Mulia, dan TK Islam Bunga Bangsa. Ketiga TK ini merupakan TK yang terakreditasi A dengan menerapkan Kurikulum PAUD 2013. TK Kartika V-11 merupakan sebuah yayasan pendidikan dalam jenjang TK yang terakreditasi A. TK Kartika V-11 didirikan pada tanah milik Korem 091 pada tanggal 16 Juli 1990. Kondisi fisik dari lokasi tersebut adalah bagaimana kawasan tersebut memberikan 
kawasan yang baik sebagai suatu lokasi yang jelas untuk ditetapkan pada kawasan tersebut dengan sangat baik dan lebih tepatnya yang jelas. Lokasi dari TK Kartika V-11 berada di Jalan Pangeran Suryanata, Kelurahan Air Putih, Kecamatan Samarinda Ulu, Samarinda, Kalimantan Timur.

TK Islam Bunga Bangsa merupakan TK yang didirikan oleh Yayasan Bunga Bangsa Samarinda yang memiliki 4 ruang kelas dan terakreditasi A. TK mulai beroperasi pada 15 Desember 2008 dengan pengelompokan anak usia 4-5 tahun kelompok A dan usia 5-6 tahun kelompok B. Lokasi dari TK ini terletak di Jalan D.I. Panjaitan No.51, Kecamatan Sungai Pinang, Kota Samarinda, Kalimantan Timur.

TK Tunas Mulia merupakan TK yang didirikan oleh Yayasan Swasembada pada 12 Desember 1978 dengan terakreditasi A. Lokasi TK terletak di Jalan Jakarta Blok I, RT 41, Kelurahan Loa Bakung, Kecamatan Sungai Kunjang, Samarinda.

\subsection{Analisis}

Kawasan taman di TK berfungsi disaat anak-anak memiliki waktu bermain. Kualitas taman pada tiga TK terdiri dari kualitas visual dan fungsional sehingga kualitas pandangan good view dan bad view menjadi faktor yang harus diperhatikan dalam mengelola taman bagi anak TK. Kondisi good view terlihat memiliki beragam permainan dan tanaman pada area permainan dan di sekitar kelas. Kondisi bad view dari terlihat dari pemilihan tanaman yang tidak kurang tepat dan kurang memberikan fungsi peneduh atau screening. Elemen tanaman dan perkerasan di kawasan TK memiliki keberagaman.

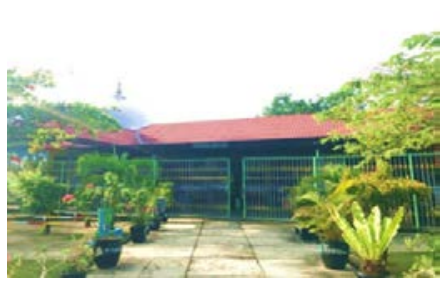

a) Good view

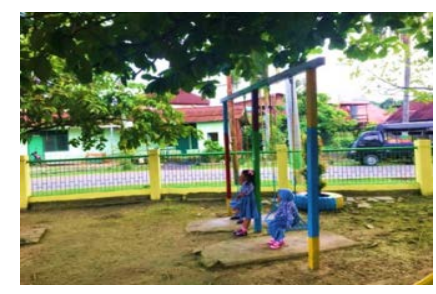

b) Bad view

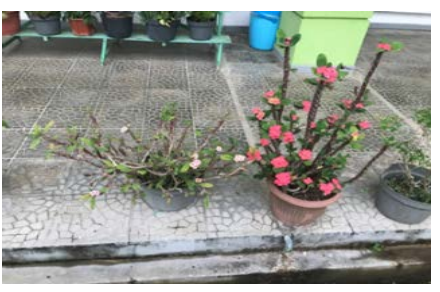

c) Tanaman Eurphobia

Gambar 2. Kondisi area taman TK

Elemen tanaman terdapat tanaman yang tidak aman untuk lokasi seperti terdapat tanaman kaktus hias (parodia magnifica) Eurphobia (Eurphobia milii). Elemen perkerasan seperti sarana permainan anak harus semakin ditingkatkan pengelolaannya karena terdapat bagian yang telah rusak dan memerlukan perawatan. Menurut Eckbo (1964) bahwa anak-anak dalam ruang bermainnya memerlukan sebuah petualangan, keragaman serta kejutan yang aman dalam permainan yang diberikan sehingga dapat mempengaruhi tingkat indera anak dan tingkat perasaan untuk mengetahui motorik anak agar lebih aktif bermain sambil belajar. Sehingga, fasilitas permainan pada tiga lokasi masih terdapat kekurangan dari kebutuhan yang diinginkan oleh anak dan permainan yang tidak dibutuhkan oleh anak. Fasilitas seperti tempat sampah masih kurang optimal di beberapa titik area lokasi permainan anak. Signboard pada lokasi TK juga terlalu informatif untuk anak mengerti dengan baik tentang informasi yang ingin diberikan oleh signboard.

\subsection{Evaluasi}

\subsubsection{Evaluasi Fisik}

Penilaian pada evaluasi fisik taman didapatkan hasil bahwa nilai komponen fisik sama dengan 0,94. Akses menuju lokasi taman mudah dilalui oleh anak-anak. Kawasan taman memiliki dominan elemen tanaman daripada elemen perkerasan sehingga memberikan kesan alami dan ruang alami untuk anak.

\subsubsection{Evaluasi Ruang-ruang Taman}

Evaluasi ruang taman diperoleh sebesar 0,67 dimana ruang taman pada lokasi taman cukup memberikan keragaman ruang untuk anak dapat menikmati kawasan dalam bersosialisasi dalam berkelompok ataupun individu dalam bermain. 


\subsubsection{Evaluasi Kualitas Taman}

Evaluasi kualitas taman diperoleh sebesar 0,62. Pengalihan positif pada area taman belum optimal karena masih terdapat beberapa sisi yang terlihat baik dan tidak baik untuk dipandang. Pemilihan warna tanaman juga masih membuat suasana monoton untuk area taman. Terdapat kurangnya penataan groundcover pada kawasan ruang bermain anak sehingga terdapat beberapa jenis permainan tidak terlalu aman ketika anak bermain karena tidak didukung groundcover yang akan berguna meminimalkan insiden terluka ketika anak terjatuh dari permainan maupun insiden lainnya.

\subsubsection{Evaluasi Elemen Taman}

Evaluasi elemen taman mendapatkan hasil sebesar 0,5. Lokasi taman terdapat beberapa jenis tanaman yang berduri yang ditanam pada pot disekitar jalur sirkulasi anak serta ditanam di area ruang bermain anak yang dapat membahayakan anak ketika anak aktif berada di kawasan permainan yang terdapat tanaman tersebut. Visual dari akses taman dari luar taman menuju dalam taman maupun sebaliknya masih terlihat kurang baik karena penataan dari tanaman yang kurang rapi.

\subsubsection{Evaluasi Terhadap Anak Pra Sekolah}

Identifikasi pada kawasan fasilitas taman dilakukan karena anak merupakan pengguna aktif pada area taman sehingga pengamatan menghasilkan data deskriptif. Pengamatan dilakukan dari hari SeninJumat dimulai pada pukul 9:30-10:00 Wita dan 07:00-07:30 Wita. Kondisi lapang anak pada tiga lokasi TK mendapatkan bahwa anak cenderung lebih menyukai bermain secara berkelompok dan memilih permainan yang banyak penggunanya. Permainan pada anak juga dapat dibagi menjadi permainan sosial antar anak dan permainan obyek dengan fokus permainan tertentu (Riddick, 1984). Sehingga, dari pengamatan pada lokasi terdapat juga anak yang cenderung individu dan lebih fokus bermain sendiri pada permainan tertentu tetapi dengan intensitas permainan yang tidak terlalu lama. Anak cenderung bermain di satu permainan yang mengendalikan kekuatan dan rasa ingin tahu dalam diri anak. Intensitas anak pada softscape sangat rendah karena kawasan taman hanya sebagai display dan peneduh tanpa anak mencoba untuk berinteraksi dengan tanaman. Anak lebih menyukai kawasan daerah yang teduh terkena sinar matahari. Anak menyukai ruang taman yang besar sehingga nyaman untuk berlari saat bermain. Jenis permainan terowongan, perosotan, memanjat tali, ayunan adalah sarana permainan yang paling diminati oleh anak sedangkan permainan yang kurang diminati adalah permainan bola dunia dan rumah jebakan.

Tabel 2. Penilaian Kondisi Lapang Pengguna Anak di ketiga lokasi TK

\begin{tabular}{ccc}
\hline E) Elemen & Pemantauan Kondisi Lapang & $\begin{array}{c}\text { Intensitas Pengguna } \\
\text { (IP*) }\end{array}$ \\
\hline A. Elemen Keras & Bola Dunia & $\mathrm{R}$ \\
& Pemanjat Tali & $\mathrm{S}$ \\
Ayunan & $\mathrm{T}$ \\
& jungkat-jungkit & $\mathrm{S}$ \\
& Rumah Jebakan & $\mathrm{R}$ \\
& & \\
B. Elemen Lunak & Pohon & $\mathrm{R}$ \\
& Perdu & $\mathrm{R}$ \\
& Semak & $\mathrm{R}$ \\
& Groundcover & $\mathrm{T}$ \\
\hline
\end{tabular}

\begin{tabular}{ccc}
\hline b) Elemen & Pemantauan Kondisi Lapang & $\begin{array}{c}\text { Intensitas Pengguna } \\
(\text { IP*) }\end{array}$ \\
\hline A. Elemen Keras & Bola Dunia & $\mathrm{R}$ \\
& Pemanjat Tali & $\mathrm{R}$ \\
& Ayunan & $\mathrm{T}$ \\
& Perosotan & $\mathrm{T}$ \\
& Terowongan & $\mathrm{T}$ \\
& Palang Besi & $\mathrm{S}$ \\
B. Elemen Lunak & Rumah Jebakan & $\mathrm{R}$ \\
& & $\mathrm{S}$ \\
& Pohon & $\mathrm{R}$ \\
& Perdu & $\mathrm{S}$ \\
Semak & $\mathrm{T}$
\end{tabular}

\begin{tabular}{|c|c|c|}
\hline Elemen & Pemantauan Kondisi Lapang & $\begin{array}{c}\text { Intensitas Pengguna } \\
\left(\mathrm{IP}^{*}\right)\end{array}$ \\
\hline \multirow[t]{6}{*}{ A. Elemen Keras } & Bola Dunia & $\mathrm{R}$ \\
\hline & Pemanjat Tali & $\mathrm{s}$ \\
\hline & Ayunan & $\mathrm{s}$ \\
\hline & Perosotan & $\mathrm{T}$ \\
\hline & Terowongan & $\mathrm{T}$ \\
\hline & Rumah Jebakan & $\mathrm{R}$ \\
\hline \multicolumn{3}{|l|}{ B. Elemen Lunak } \\
\hline & Pohon & $\mathrm{R}$ \\
\hline & Perdu & $\mathrm{R}$ \\
\hline & Semak & $\mathrm{R}$ \\
\hline & Groundcover & $\mathrm{T}$ \\
\hline
\end{tabular}

Keterangan Intensitas Pengguna :

$\left.\mathrm{IP}^{*}\right)$ : Intensitas Pengguna

Sumer $\mathrm{S}, \mathrm{S}=$ Sedang, $\mathrm{T}=$ Ting

a) TK Kartika V-11, b) TK Islam Bunga Bangsa, c) TK Tunas Mulia 
Berdasarkan hasil penelitian yang penulis dapatkan pada lokasi TK tersebut adalah anak laki-laki lebih mendominasi permainan perosotan dan terowongan tetapi dengan intensitas yang tidak lama (sedang=20-30 menit) karena anak laki-laki akan lebih menyukai bermain bersama anak laki-laki lainnya dengan bermain kejar-kejaran hingga waktu istirahat berakhir. Terdapat beberapa anak laki-laki 4-5 orang yang lebih menyukai bermain bola dunia, panjat tali dan perosotan. Anak perempuan lebih menyukai bermain dengan teman perempuan dengan membentuk 2-5 orang kelompok main. Anak perempuan akan menyukai permainan ayunan dan perosotan, tetapi terdapat anak perempuan yang berani berkelompok untuk bermain menaiki palang besi dan memanjat tali.

\subsection{Sintesis}

Berdasarkan hasil kuesioner yang diberikan kepada 30 responden pada ketiga lokasi TK. Diketahui bahwa sebanyak $(93,33 \%)$ responden adalah wanita yang bekerja sebagai pengajar di sekolah dan sebanyak $(6,67 \%)$ responden pria yang merupakan gardener pada lokasi TK.

Tabel 3. Hasil Rekapitulasi Penilaian Aktual, Konfirmasi Responden, dan Verifikasi Pengamatan Perilaku Pengguna

\begin{tabular}{|c|c|c|c|c|c|c|c|c|}
\hline \multirow[b]{2}{*}{ No } & \multirow[b]{2}{*}{ Komponen } & \multirow[b]{2}{*}{ Indikator } & \multicolumn{2}{|c|}{ Pemantauan Kondisi Aktual } & \multicolumn{4}{|c|}{ Evaluasi } \\
\hline & & & Kualitas Standar & Nilai Aktual & Nilai Standar & KPI & E* & $\mathrm{R}^{* *}$ \\
\hline \multirow[t]{10}{*}{1} & Fisik & Aksesibilitas & Kemudahan lokasi dan akses & & & & & \\
\hline & & & pintu masuk & 3 & 3 & & & \\
\hline & & & dapat dilalui oleh pengguna & & & & & \\
\hline & & & dengan baik & 3 & 3 & & & \\
\hline & & Sirkulasi & Kondisi fisik jalur dengan warna & & & & & \\
\hline & & & tekstur yang menarik & 2 & 3 & E1 & & R1 \\
\hline & & & lebar sesuai dengan fungsi dan & 3 & 3 & & & \\
\hline & & Area & Penekanan terhadap aspek alami & 3 & 3 & & & \\
\hline & & & Material hijau yang merata & 3 & 3 & & & \\
\hline & & & Jumlah & 17 & 18 & 0,94 & & \\
\hline \multirow[t]{9}{*}{2} & Kualitas Taman & Pemandangan & Penekanan kesan alami & 3 & 3 & & & \\
\hline & & & $\begin{array}{l}\text { Menyediakan pengalihan yang } \\
\text { positif dan menstimulasi indera } \\
\text { dengan jarak pandang yang jelas }\end{array}$ & 2 & 3 & E2 & & R2 \\
\hline & & Pencahayaan & Tidak gelap, sinar matahari cukup & 2 & 3 & & & \\
\hline & & & Bayangan alami & 2 & 3 & & & \\
\hline & & Warna & $\begin{array}{l}\text { Tidak monoton, perpaduan warna } \\
\text { secara kreatif }\end{array}$ & 1 & 3 & & & \\
\hline & & Kemananan & $\begin{array}{l}\text { Memberikan rasa aman dan tidak } \\
\text { berbahaya pada elemen }\end{array}$ & 2 & 3 & E3 & & R3 \\
\hline & & Kenyamanan & $\begin{array}{l}\text { Kenyamanan suhu dan } \\
\text { kenvamanan fisiologis }\end{array}$ & 1 & 3 & & & \\
\hline & & & $\begin{array}{l}\text { Desain (site furniture) jelas dan } \\
\text { nyaman }\end{array}$ & 2 & 3 & & & \\
\hline & & & Jumlah & 15 & 24 & 0,62 & & \\
\hline \multirow[t]{7}{*}{3} & $\begin{array}{l}\text { Ruang-ruang } \\
\text { Taman }\end{array}$ & Desain & $\begin{array}{l}\text { Terorientasi (terlihat) dengan } \\
\text { pengguna }\end{array}$ & 2 & 3 & & & \\
\hline & & Jenis/macam & Kesempatan untuk membuat & & & & & \\
\hline & & & pilihan dan mencari ruang privasi, & 2 & 3 & & & \\
\hline & & & kesempatan untuk bersosialisasi & & & & & \\
\hline & & Luasan & Tidak sempit, nyaman & 2 & 3 & & & \\
\hline & & Sirkulasi & Nyaman, tidak panas & 2 & 3 & & & \\
\hline & 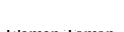 & & Jumlah & 8 & 12 & 0,67 & & \\
\hline 4 & & Softscape & & & & & & \\
\hline & & Jenis/macam & Tanaman lokal, keragaman spesies & 2 & 3 & & & \\
\hline & & Bentuk & Ornamental & 1 & 3 & & & \\
\hline & & Keamanan & tidak toksis, tidak berduri & 1 & 3 & & E4 & R4 \\
\hline & & $\begin{array}{l}\text { Kesesuaian lokasi } \\
\text { fungsi }\end{array}$ & ;/ sesuai dengan lokasi/fungsinya & 1 & 3 & & & \\
\hline & & Pemeliharaan & Mudah dipelihara & 2 & 3 & & & \\
\hline & & Keindahan & Warna, bentuk & 1 & 3 & & & \\
\hline & & Hardscape & & & & & & \\
\hline & & Jenis & $\begin{array}{l}\text { Jahur jalan dan site furniture } \\
\text { (playground, bangku taman, } \\
\text { signboard, tempat sampah, dil) }\end{array}$ & 2 & 3 & & E5 & R5 \\
\hline & & Bentuk & $\begin{array}{l}\text { memiliki bentuk beragam/ } \\
\text { bertekstur }\end{array}$ & 2 & 3 & & E6 & R6 \\
\hline & & Keamanan & tidak licin, tidak rusak & 1 & 3 & & & \\
\hline & & Kondisi & berfungsi dengan baik & 2 & 3 & & & \\
\hline & & & Jumlah & 15 & 30 & 0,5 & & \\
\hline \multirow[t]{5}{*}{5} & $\begin{array}{l}\text { Pengelola/ } \\
\text { Pengajar dan }\end{array}$ & $\begin{array}{l}\text { Umur Pengajar/ } \\
\text { pengelola }\end{array}$ & Semua golongan umur & 2 & 3 & & & \\
\hline & aktivitas & Jenis Aktivitas & $\begin{array}{l}\text { Mendukung aktivitas aktif dan } \\
\text { pasif }\end{array}$ & 1 & 3 & & & \\
\hline & & & $\begin{array}{l}\text { Aktivitas sesuai dengan fungsi dan } \\
\text { elemen }\end{array}$ & 2 & 3 & & & \\
\hline & & & Jumlah & 5 & 9 & 0,57 & & \\
\hline & & & NILAI KPI & 60 & 93 & 0,64 & & \\
\hline
\end{tabular}


Berdasarkan tabel diatas didapatkan bahwa total nilai dari nilai $\mathrm{KPI}$ adalah $\mathrm{KPI}<1(\mathrm{KPI}=0,64)$ sehingga dapat disimpulkan bahwa kondisi taman tidak sesuai dengan kriteria yang sudah ditetapkan berdasarkan kriteria desain fungsional menurut Marcus (2000), Marcus dan Barnes (2008), McDowell dan McDowell (2008) dan Stigsdotter dan Grahn (2002). Pada tabel 3, dapat terlihat bahwa terdapat 6 poin rekomendasi terkait nilai fungsional dan estetika pada ketiga taman di TK.

\subsubsection{Rekomendasi umum pada lokasi}

Rekomendasi umum yang diusulkan untuk taman TK yang lebih baik, yaitu sebagai berikut: 1) Penataan tanaman pada jalur sirkulasi yang lebih jelas dan variasi tanaman lebih beragam dan memiliki proporsi yang baik untuk meningkatkan kecerdasan naturalis dan visual spasial anak; 2) Perlunya penambahan dan pengelolaan tanaman yang memberikan efek bayangan yang teduh dan menjadi sarana permainan aktif (kecerdasan intrapersonal dan interpersonal); 3) Perlunya penataan pola penanaman agar tanaman terkesan rapi dan pemilihan jenis tanaman yang menjadi sarana edukasi aktif (kecerdasan visual spasial dan naturalis); 4) Perlunya penambahan bentuk fasilitas playground dengan tema alami agar anak lebih aktif mengasah motorik (kecerdasan kinestetik); 5) Perlunya mengatur pemilihan tanaman yang tidak berbahaya/berduri pada taman anak (kecerdasan naturalis); 6) Perlunya penambahan fasilitas taman seperti tempat sampah dan signboard yang jelas (kecerdasan verbal linguistik)

\subsubsection{Rekomendasi Khusus dari Pengajar/Pengelola TK}

Rekomendasi khusus adalah taman bukan hanya sebagai area bermain anak TK tetapi dapat juga menjadi sarana edukasi aktif dalam pertumbuhan anak sehingga anak semakin dapat mengembangkan pola pemikirannya pada konsep mecintai lingkungan. Taman TK juga dapat menjadi salah satu penyumbang untuk Ruang Terbuka Hijau di tengah kota/pemukiman.

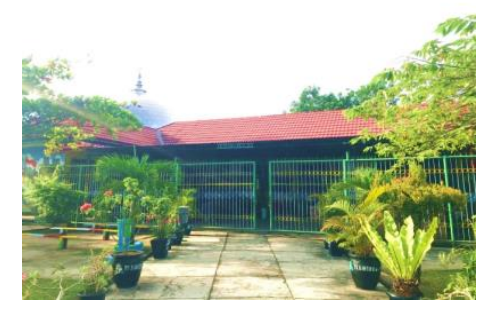

(a) Pintu masuk taman eksisting

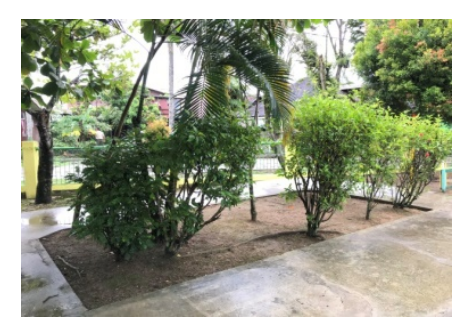

(c) semak tinggi tanaman kembang sepatu (Hibricus sp.)

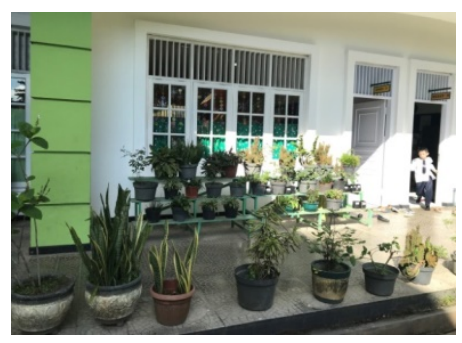

(e) Penataan dan visual Tanaman di depan kelas eksisting

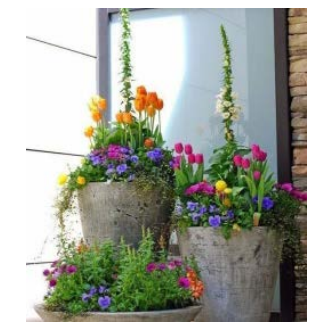

(b) Rekomendasi umum penanaman

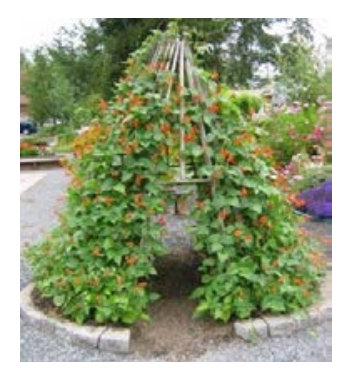

(d) Rekomendasi umum penanaman menjadi sarana permainan

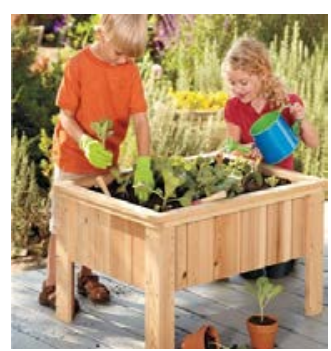

(f) Rekomendasi umum penataan sehingga anak lebih aktif dengan tanaman 


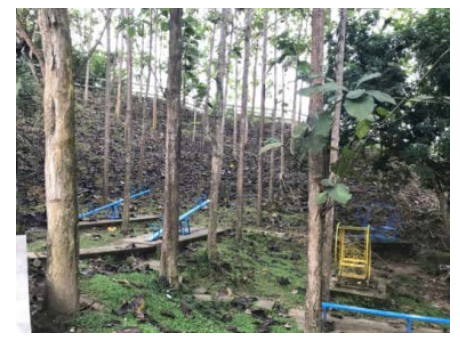

(g) Pepohonan eksisting pada lokasi taman

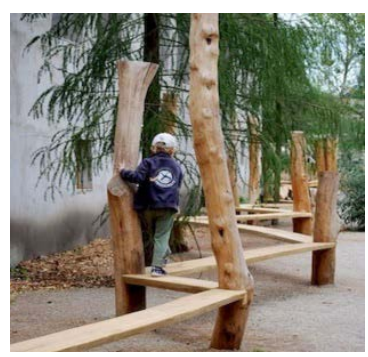

(h) Rekomendasi umum permainan yang menggunakan pepohonan

Gambar 3. Rekomendasi Umum Lokasi TK

\section{Simpulan dan Saran \\ 4.1 Simpulan}

Taman pada TK merupakan sebuah ruang bermain outdoor yang merupakan pelengkap pada fasilitas bermain anak. Taman pada tiga lokasi TK yaitu TK Tunas Mulia, TK Islam Bunga Bangsa, TK Kartika V-11 belum sesuai standar dengan tuntutan Kurikulum 2013 khususnya dalam pengenalan akan lingkungan alam. Ruang terbuka taman pada TK masih sebatas sebagai sebuah pendukung sekolah menjadi kawasan hijau tanpa melibatkan taman menjadi sarana edukasi aktif bagi anak. Berdasarkan nilai kriteria desain fungsional yang didapatkan di tiga lokasi TK memperoleh nilai key performance index (KPI) sebesar 0,64 dari skala 0-1 sehingga disimpulkan taman tidak sesuai kriteria yang baik untuk lingkungan anak. Konfirmasi dari responden berdasarkan kuesioner yang memberikan hasil rekomendasi pada tahapan elemen taman, seperti pemilihan tanaman yang berbunga dan aman, penyediaan signboard yang baik, penyediaan fasilitas permainan yang edukatif untuk anak dan menyatu dengan lingkungan sekitar.

\subsection{Saran}

Hasil studi ini diharapkan dapat menjadi pertimbangan bagi pihak pengelola/pengajar pendidikan anak untuk keberlanjutan dan penerapan taman yang baik secara fungsional dan estetika pada taman anak disekolah. Hasil studi diharapkan sebagai berikut: 1) Menjadi masukan bagi pengembangan taman bermain bagi anak TK yang memiliki perencanaan dan pemeliharan untuk menjadikan taman bukan sekedar area hijau tetapi dapat menjadi kawasan yang berfungsi edukatif mengembangkan pengetahuan belajar sambil bermain bagi anak; 2) Menjadi rujukan dan mengoptimalkan potensi kawasan taman di TK tersebut menjadi TK yang semakin memiliki kualitas untuk ikut serta memelihara lingkungan alam pada sekolah TK di wilayah kota Samarinda; 3) Mendorong peran pengelola/pengajar dari pihak sekolah serta lembaga terkait yaitu Dinas Pendidikan untuk dapat memahami dan mengelola penerapan fasilitas lingkungan alam yang lebih baik lagi agar anak-anak sejak kecil dapat semakin mengerti dan memahami untuk menjaga lingkungan dengan baik dimulai dari anak-anak usia dini.

\section{Daftar Pustaka}

Arifin HS, A. Munandar, N.H.S, Arifin, Q, Pramukanto, V.D. Damayanti. (2008). Sampoerna Hijau Kotaku Hijau. Bogor: Sampoerna Hijau.

Eckbo, G. (1964). Urban Landscape Design. McGraw-Hill Book Co. New York. 298 p.

Kementerian Pendidikan dan Kebudayaan Republik Indonesia. (2013). Buku Panduan Pendidik Kurikulum 2013 PAUD Anak Usia 4-5 Tahun. 2014. Kementerian Pendidikan dan Kebudayaan Republik Indonesia Jakarta.

Marcus, C.C. dan M. Barnes. (1999). Gardens in Healthcare Facilities: Uses, Therapeutic Benefits, and

Design Recommendations. The Center for Health Design, Inc. CA.

McDowell C.F. dan T.C.McDowell. (2008). The Sanctuary Garden. Di dalam: Kreitzer MJ. Healing by Design: Healing Garden and Therapeutic Landscapes. Informedesign: Implications, 02 (10): 1-6. 
Moore, R. C. (1990). Plants for play: A plant selection guide for children's outdoor environments. MIG Communications. Berkeley, California.

Riddick, B. (1984). Toys and Plant for the Handicapped Child. Billing and Sons Ltd. London. $138 \mathrm{p}$.

Stigsdotter UA dan P. Grahn. (2002). What Makes a Garden a Healing Garden. Amer. Hort. Therap. Assoc. 13: $60-68$. 